\title{
Lifestyle in progression from hypertensive disorders of pregnancy to chronic hypertension in Nurses' Health Study II: observational cohort study
}

\author{
Simon Timpka, ${ }^{1,2,3}$ Jennifer J Stuart, ${ }^{1,4}$ Lauren J Tanz, ${ }^{1,4}$ Eric B Rimm, ${ }^{2,4,5,6}$ Paul W Franks, ${ }^{3,5}$ \\ Janet W Rich-Edwards ${ }^{1,2,4}$
}

${ }^{1}$ Connors Center for Women's Health and Gender Biology,

Brigham and Women's Hospital, Boston, MA, USA

${ }^{2}$ Harvard Medical School, Boston, MA, USA

${ }^{3}$ Lund University Diabetes Center, Department of Clinical

Sciences Malmö, Lund University, Malmö, Sweden

${ }^{4}$ Department of Epidemiology, Harvard T.H. Chan School of

Public Health, Boston, MA, USA

${ }^{5}$ Department of Nutrition,

Harvard T.H. Chan School of

Public Health, Boston, MA, USA

${ }^{6}$ Channing Division of Network

Medicine, Department of

Medicine, Brigham and

Women's Hospital, Boston,

MA, USA

Correspondence to: STimpka simon.timpka@med.lu.se

Additional material is published online only. To view please visit the journal online.

Cite this as: $B M J$ 2017;358:j3024 http://dx.doi.org/10.1136/bmi.j3024

Accepted: 14 June 2017

\section{ABSTRACT}

OBJECTIVES

To study the association between lifestyle risk factors and chronic hypertension by history of hypertensive disorders of pregnancy (HDP: gestational hypertension and pre-eclampsia) and investigate the extent to which these risk factors modify the association between HDP and chronic hypertension.

DESIGN

Prospective cohort study.

SETTING

Nurses' Health Study II (1991-2013).

\section{PARTICIPANTS}

54588 parous women aged 32 to 59 years with data on reproductive history and without previous chronic hypertension, stroke, or myocardial infarction.

\section{MAIN OUTCOME MEASURE}

Chronic hypertension diagnosed by a physician and indicated through nurse participant self report. Multivariable Cox proportional hazards models were used to investigate the development of chronic hypertension contingent on history of HDP and four lifestyle risk factors: post-pregnancy body mass index, physical activity, adherence to the Dietary Approaches to Stop Hypertension (DASH) diet, and dietary sodium/potassium intake. Potential effect modification (interaction) between each lifestyle factor and previous HDP was evaluated with the relative excess risk due to interaction.

RESULTS

$10 \%(n=5520)$ of women had a history of HDP at baseline. 13971 cases of chronic hypertension

\section{WHAT IS ALREADY KNOWN ON THIS TOPIC \\ Women with a history of hypertensive disorders of pregnancy (HDP) are at increased risk for chronic hypertension and cardiovascular disease \\ Healthier lifestyle can reduce the risk of chronic hypertension in the general population}

\section{WHAT THIS STUDY ADDS}

Women aged 32-59 years with previous HDP seem to have similar benefit from physical activity and adhering to dietary guidelines compared with parous women with only normotensive pregnancies

Overweight and obesity seem to be more detrimental in the progression to chronic hypertension in women with a history of HDP than in women without such a history

As for women with gestational diabetes mellitus, clinicians should especially help women with a history of HDP to attain, and maintain, a healthy weight after pregnancy occurred during 689988 person years of follow-up. Being overweight or obese was the only lifestyle factor consistently associated with higher risk of chronic hypertension. Higher body mass index, in particular, also increased the risk of chronic hypertension associated with history of HDP (relative excess risk due to interaction $\mathrm{P}<0.01$ for all age strata). For example, in women aged 40-49 years with previous HDP and obesity class I (body mass index 30.0-34.9), $25 \%$ (95\% confidence interval $12 \%$ to $37 \%$ ) of the risk of chronic hypertension was attributable to a potential effect of obesity that was specific to women with previous HDP. There was no clear evidence of effect modification by physical activity, DASH diet, or sodium/potassium intake on the association between HDP and chronic hypertension.

\section{CONCLUSION}

This study suggests that the risk of chronic hypertension after HDP might be markedly reduced by adherence to a beneficial lifestyle. Compared with women without a history of HDP, keeping a healthy weight seems to be especially important with such a history.

\section{Introduction}

High blood pressure is a leading cause of disease in the world and an important modifiable risk factor for cardiovascular disease. ${ }^{12}$ Between $5 \%$ and $10 \%$ of parous women have a history of hypertensive disorders of pregnancy (HDP: pre-eclampsia and gestational hypertension), ${ }^{34}$ which is associated with earlier onset of chronic hypertension and a higher risk of ischemic heart disease and stroke. ${ }^{5-7}$ Women with previous HDP may benefit from early screening for cardiovascular disease and its risk factors, ${ }^{289}$ as they have a more adverse cardiovascular risk profile in middle age. ${ }^{10}$

Despite calls for increased screening of cardiovascular risk factors, ${ }^{11}$ including chronic hypertension, little guidance exists regarding the prevention of chronic hypertension among women with a history of HDP. Furthermore, the role of lifestyle in the progression from HDP to chronic hypertension is largely unknown. ${ }^{12}$ In particular, whether established lifestyle interventions are as effective in women with a history of HDP as in the general population is unclear. Observational data can, in this setting, both inform the design of future trials and provide complementary evidence in the development of clinical prevention guidelines.

In this study, we first examined the association of four established lifestyle risk factors for high blood 
pressure (body mass index, ${ }^{13}$ physical activity, ${ }^{14} 15$ adherence to the Dietary Approaches to Stop Hypertension (DASH) diet, ${ }^{16} 17$ and dietary sodium/ potassium intake ${ }^{18}$ ) with the development of chronic hypertension by history of HDP. We then investigated the extent to which progression from HDP to chronic hypertension is modified by each lifestyle factor.

\section{Methods}

We included parous women with complete reproductive history from the Nurses' Health Study II, a prospective cohort study that recruited 116429 femaleUS registered nurses aged 25-42 years in 1989. These women were free of known cancer (excluding benign skin cancer) at recruitment and were sent questionnaires biennially. Participants in the study, irrespective of parity, between 1991-the first year the women filled out food frequency questionnaires-and 2013 were considered potentially eligible $(n=115048)$. Cohort participants provided detailed data on their complete reproductive history on the 2009 questionnaire, including whether and when they had been diagnosed as having gestational hypertension or pre-eclampsia. Of these responders ( $n=76840)$, we excluded 13253 nulliparous women and 4153 women who had had chronic hypertension, myocardial infarction, or stroke before they were eligible to enter the analyses, leaving 59434 potentially eligible women. For the purpose of this study, we restricted age during follow-up to 32-59 years as few eligible women were outside this age range. Exclusion of women who did not meet the specific analytic inclusion criteria for any covariate updated time period (as described below) resulted in 54588 parous women aged 32-59 years entering this analysis.

\section{Ascertainment of HDP, lifestyle exposures, and chronic hypertension}

We classified nurse participants as having a history of HDP after the first of any pregnancy lasting at least 20 weeks that they self reported to have been complicated by a diagnosis of gestational hypertension or pre-eclampsia. Maternal recall of HDP has fairly high sensitivity, and the quality does not seem to be uniformly affected by time since pregnancy. ${ }^{19}$

Women retrospectively recalled their weight at age 18 years and reported their current height at the start of the study in 1989 and their current weight at each subsequent questionnaire; all of these anthropometric variables have shown high correlation with clinical measurements in validation sub-studies of nurse participants. $^{20} 21$ We calculated body mass index as weight in $\mathrm{kg}$ divided by height in $\mathrm{m}$ squared $(\mathrm{kg} /$ $\mathrm{m}^{2}$ ) and categorized it into six groups: underweight (<18.5), low (18.5-22.4) and high (22.5-24.9) normal weight, overweight (25.0-29.9), class I obesity (30.034.9), and class II/III obesity ( $\geq 35.0){ }^{22}$ We excluded women with calculated body mass index below 15 or above 50. Physical activity was based on total leisure time physical activity per week (with specific activities characterized by metabolic equivalents (METs)) and updated every four to six years. ${ }^{23}$ Diet was reported using food frequency questionnaires and re-evaluated every other questionnaire cycle. As described elsewhere, ${ }^{24}$ we derived an energy adjusted DASH diet score based on adherence to the DASH guidelines. We used the energy adjusted sodium/potassium intake (that is, density), as questionnaires are better at quantifying sodium/potassium intake than they are at quantifying dietary sodium, ${ }^{25}$ and, like sodium, the sodium/potassium intake is associated with higher blood pressure. ${ }^{18}$ Variables were generally carried forward for up to four cycles if missing. The only exception among the lifestyle exposures was body mass index, which was carried forward for only two cycles as current weight was asked on every questionnaire.

In 1989 women reported whether they had ever been diagnosed as having hypertension outside of pregnancy (here referred to as "chronic hypertension" to distinguish it from hypertension in pregnancy) and, with each subsequent questionnaire, they were asked to report any new diagnosis. Self reported diagnosis by a physician of chronic hypertension has been shown to be reliable in this cohort. ${ }^{26}$

\section{Statistical analyses}

We used multivariable Cox proportional hazards models to estimate hazard ratios and 95\% confidence intervals for the association between each lifestyle factor and chronic hypertension, by history of HDP. Each Cox model was stratified by questionnaire cycle and age.

Women were eligible to enter the analyses if they were parous and 32 years of age or older; women contributed person time beginning in 1991 or at the questionnaire cycle after they became eligible (that is, had their first birth and/or turned 32). Women were censored at report of chronic hypertension (the outcome of interest), confirmed myocardial infarction or stroke, last returned questionnaire, death, upper age limit, or end of follow-up. Periods of ineligible person time-for example, when a woman was pregnant, reported antihypertensive drug use (in the absence of a diagnosis of chronic hypertension), had not reported lifestyle data before the period, or the period was past the carry forward horizon of covariates-were not included in the analyses.

To estimate effect modification by lifestyle from the Cox models correctly (as described below), there should be no two way or three way multiplicative interactions of HDP or lifestyle with age. As this assumption did not hold for any of the lifestyle factors across the full age range $(\mathrm{P}<0.001)$, we instead modeled associations separately in three age categories: 32 to 39,40 to 49 , and 50 to 59 years. On the basis of tests of the age interactions within these finer age strata, we assumed proportional hazards.

To evaluate the association between each lifestyle factor (body mass index, physical activity, DASH diet, and sodium/potassium intake) and chronic hypertension by previous HDP status, we used Cox models that included multiplicative interaction terms 
between HDP status and the index lifestyle factor. We included covariates on the basis of a priori assumptions about their roles as either confounders or mediators. The base models were adjusted for age, race/ethnicity, and parity (that is, non-modifiable risk factors for HDP and chronic hypertension). The adjusted models additionally included body mass index at age 18; updated smoking status, alcohol use, non-steroidal anti-inflammatory drug use, menopausal status, and history of gestational diabetes mellitus; and each of the lifestyle variables (updated body mass index, physical activity, DASH diet, and sodium/potassium intake) and multiplicative interactions terms for HDP history and the lifestyle factor under investigation in that particular model. In the analyses focusing on modification by sodium/potassium intake, we controlled for quarters of whole grain and saturated fat intake instead of DASH diet, as the DASH diet score includes sodium intake. Relevant covariates (for example, body mass index but not race/ethnicity) were also allowed to be updated every cycle.

To test for effect modification by each lifestyle factor, we used an established SAS macro to calculate multiplicative interactions and the relative excess risk due to interaction (RERI) between lifestyle and history of $\mathrm{HDP},{ }^{27}$ with RERI being our main focus. We also calculated two additional additive interaction statistics (attributable proportion and synergy index) to further support any interaction identified by the RERI. ${ }^{28}$ In the analyses of effect modification by body mass index, we excluded underweight women to allow women with low normal weight (body mass index 18.5 to 22.4) to serve as the reference group. ${ }^{29}$ We used SAS 9.4 for all statistical analyses.

\section{Patient involvement}

No patients were directly involved in setting the research question or the outcome measures, nor were they involved in developing plans for recruitment, design, or implementation of this specific study. No patients were asked to advise on interpretation or writing up of results. The results of the research conducted in the Nurses' Health Study II are regularly reported to study participants.

\section{Results}

In total, 13971 cases of chronic hypertension occurred during 689988 person years of follow-up. Table 1 shows the characteristics of women by status at study entry. Ten per cent of women had a history of HDP in any pregnancy. Although women with and without a history of HDP were similar in most characteristics, those with hypertensive pregnancies had higher body mass index at study entry and were more likely to have a history of gestational diabetes and parents with a history of chronic hypertension. However, physical activity, DASH diet score, and sodium/potassium intake were similar between the two groups.

Figure 1 shows estimated incidence curves for chronic hypertension by varying levels of lifestyle factors and history of HDP. Women with previous
HDP and low normal weight (body mass index 18.5 to 22.4) had a higher cumulative incidence of chronic hypertension than did women without HDP of the same weight but less than that of women with obesity class I (body mass index 30.0 to 34.9) without a history of HDP (figure 1, top left panel). For the lifestyle factors other than body mass index, the basic cumulative incidence of chronic hypertension seemed to be higher in women with a history of HDP than in women without HDP, regardless of lifestyle. We observed similar results when HDP was plotted separately for pre-eclampsia and gestational hypertension (data not shown).

\section{Lifestyle factors in development of chronic} hypertension by history of HDP

Tables 2 and 3 show the adjusted hazard ratios for the association between lifestyle risk factors and chronic hypertension within each category of HDP history by age. Higher body mass index was associated with a greater risk of chronic hypertension regardless of HDP history and in all age groups (table 2). This was also evident within the normal range of body mass index regardless of HDP history; women with high normal body mass index had a higher hazard ratio for chronic hypertension than those with low normal body mass index (for example, women aged 32-39 years, without history of HDP, and with body mass index 22.5-24.9: hazard ratio 1.92 , 95\% confidence interval 1.45 to 2.54). The associations of other lifestyle risk factors with chronic hypertension were inconsistent across age and HDP strata (table 3). In women without a history of HDP, worse adherence to the DASH diet was associated with chronic hypertension, as was, to a lesser extent, higher sodium/potassium intake. The hazard ratios shown in tables 2 and 3 convey the association between each lifestyle exposure and chronic hypertension within each category of HDP and are not suitable for estimating differences in association between categories of HDP history. In the next section, we present the results of the effect modification (interaction) analyses, which are relevant for comparing associations between women with and without a history of HDP. All associations from the basic models adjusted only for age, race/ethnicity, and parity, which generally were of greater magnitude, are shown in supplementary tables A and B.

\section{Effect modification by lifestyle on association between HDP history and chronic hypertension}

The analyses of effect modification by lifestyle factors on the association between HDP and chronic hypertension (interaction analyses) are summarized to the right in tables 2 and 3. When we considered body mass index and previous HDP jointly on the additive scale, we observed effect modification $(\mathrm{P}<0.01)$ in all age strata. With consistently positive RERIs (supplementary table $\mathrm{C}$ ), our results indicate that body mass index in the years after pregnancy modifies the association between previous HDP and risk of chronic hypertension in women. These RERI analyses quantify effect modification (interaction) on 


\begin{tabular}{|c|c|c|}
\hline Characteristic & No HDP $(n=49068)$ & $\operatorname{HDP}(n=5520)$ \\
\hline Mean (SD) age, years & $39.2(4.1)$ & $38.6(4.1)$ \\
\hline History of pre-eclampsia* & NA & $3719(67.3)$ \\
\hline History of gestational hypertension* & NA & $2996(54.2)$ \\
\hline History of gestational diabetes mellitus & $2186(4.5)$ & $502(9.1)$ \\
\hline Mean (SD) body mass index at age 18 (457 (0.8\%) missing) & $20.8(2.7)$ & $21.6(3.2)$ \\
\hline Parental history of chronic hypertension & $23756(48.4)$ & $3061(55.5)$ \\
\hline Mean (SD) body mass index & $24.2(4.6)$ & $26.4(5.7)$ \\
\hline \multicolumn{3}{|l|}{ Categorical body mass index: } \\
\hline$<18.5$ & $1168(2.4)$ & $65(1.2)$ \\
\hline $18.5-22.4$ & $20326(41.4)$ & $1469(26.6)$ \\
\hline $22.5-24.9$ & $12087(24.6)$ & $1276(23.1)$ \\
\hline $25.0-29.9$ & $10080(20.5)$ & $1477(26.8)$ \\
\hline $30.0-34.9$ & $3600(7.3)$ & $717(13.0)$ \\
\hline$\geq 35.0$ & $1807(3.7)$ & $516(9.3)$ \\
\hline Median (interquartile range) physical activity, METs/week & $11.8(4.8-25.2)$ & $11.2(4.4-24.2)$ \\
\hline \multicolumn{3}{|l|}{ Categorical physical activity: } \\
\hline Fourth quarter-high activity & $11826(24.1)$ & $1281(23.2)$ \\
\hline Third quarter & $12281(25.0)$ & $1349(24.4)$ \\
\hline Second quarter & $12555(25.6)$ & $1412(25.6)$ \\
\hline First quarter-low activity & $12406(25.3)$ & $1478(26.8)$ \\
\hline Mean (SD) DASH diet score & $23.6(4.9)$ & $23.5(4.8)$ \\
\hline \multicolumn{3}{|l|}{ Categorical DASH diet score: } \\
\hline Fourth quarter-high adherence & $11199(22.8)$ & $1172(21.2)$ \\
\hline Third quarter & $13721(28.0)$ & $1580(28.6)$ \\
\hline Second quarter & $10788(22.0)$ & $1287(23.3)$ \\
\hline First quarter-low adherence & $13360(27.2)$ & $1481(26.8)$ \\
\hline Median (interquartile range) sodium/potassium intake & $0.72(0.62-0.84)$ & $0.73(0.62-0.85)$ \\
\hline \multicolumn{3}{|l|}{ Categorical sodium/potassium intake: } \\
\hline First quarter-low intake & $11381(23.2)$ & $1250(22.6)$ \\
\hline Second quarter & $12346(25.2)$ & $1360(24.6)$ \\
\hline Third quarter & $12714(25.9)$ & $1400(25.4)$ \\
\hline Fourth quarter-high intake & $12627(25.7)$ & $1510(27.4)$ \\
\hline \multicolumn{3}{|l|}{ Race/ethnicity: } \\
\hline White & $45737(93.2)$ & $5168(93.6)$ \\
\hline African-American & $498(1.0)$ & $69(1.3)$ \\
\hline Latina & $627(1.3)$ & $79(1.4)$ \\
\hline Asian & $701(1.4)$ & $49(0.9)$ \\
\hline Other & $776(1.6)$ & $70(1.3)$ \\
\hline Missing & 729 (1.5) & $85(1.5)$ \\
\hline \multicolumn{3}{|l|}{ Non-steroidal anti-inflammatory drug use: } \\
\hline None & $31918(65.0)$ & $3281(59.4)$ \\
\hline Past & $3153(6.4)$ & $394(7.1)$ \\
\hline Current & $13997(28.5)$ & $1845(33.4)$ \\
\hline \multicolumn{3}{|l|}{ Alcohol intake: } \\
\hline None & $20453(41.7)$ & $2514(45.5)$ \\
\hline $1-15 \mathrm{~g} /$ day & $26684(54.4)$ & $2822(51.1)$ \\
\hline$>15 \mathrm{~g} /$ day & $1931(3.9)$ & $184(3.3)$ \\
\hline \multicolumn{3}{|l|}{ Smoking status: } \\
\hline Never & $32889(67.0)$ & $3685(66.8)$ \\
\hline Past & $11370(23.2)$ & $1267(23.0)$ \\
\hline Current & $4809(9.8)$ & $568(10.3)$ \\
\hline \multicolumn{3}{|l|}{ Parity: } \\
\hline 1 birth & $9028(18.4)$ & $1146(20.8)$ \\
\hline 2 births & $24100(49.1)$ & $2634(47.7)$ \\
\hline$\geq 3$ births & $15940(32.5)$ & $1740(31.5)$ \\
\hline \multicolumn{3}{|l|}{ Menopausal status: } \\
\hline Premenopause & $46791(95.4)$ & $5265(95.4)$ \\
\hline Postmenopause & $1949(4.0)$ & $207(3.8)$ \\
\hline Not sure & $328(0.7)$ & $48(0.9)$ \\
\hline
\end{tabular}




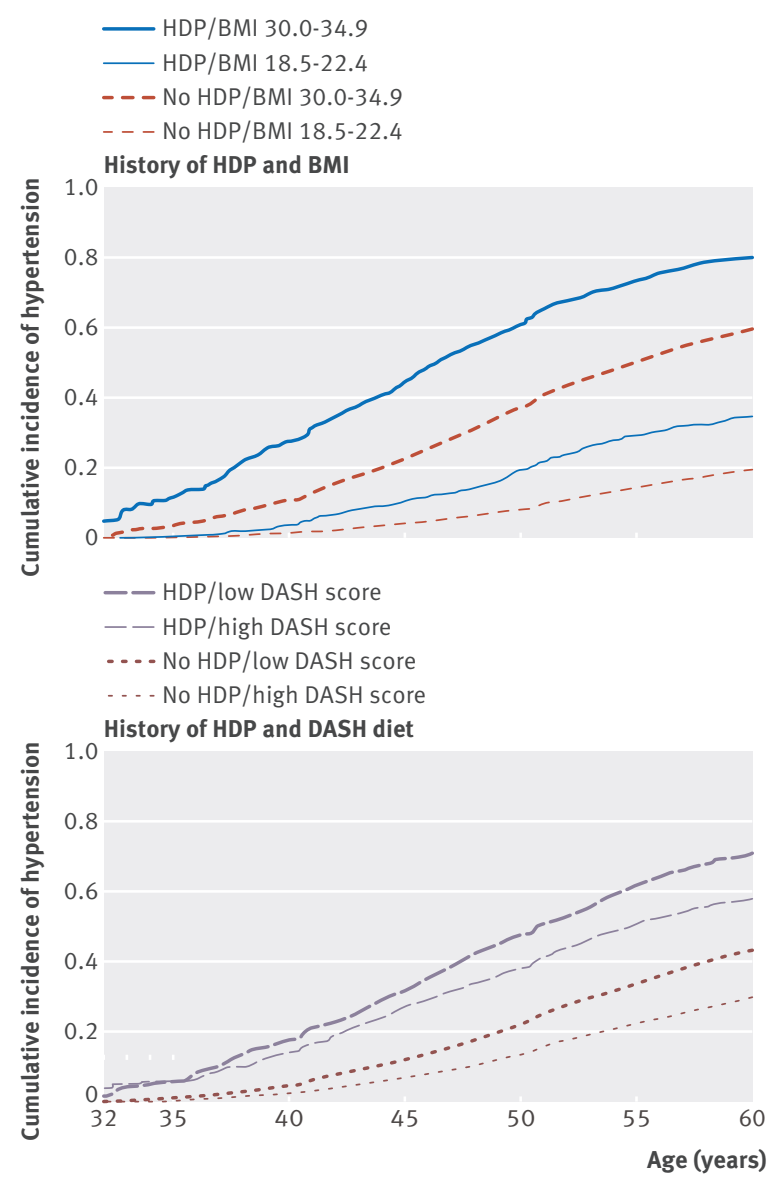

$$
\begin{aligned}
& -- \text { HDP/low physical activity } \\
& --- \text { HDP/high physical activity } \\
& -- \text { No HDP/low physical activity } \\
& -- \text { No HDP/high physical activity } \\
& \text { History of HDP and physical activity }
\end{aligned}
$$

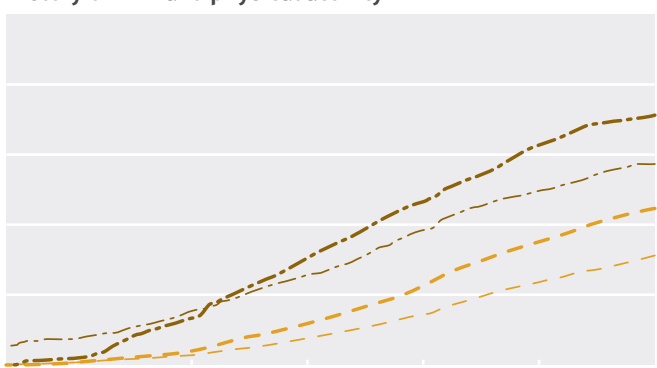

-..- HDP/high sodium/potassium intake

-.- HDP/low sodium/potassium intake

- - - No HDP/high sodium/potassium intake

- - - No HDP/low sodium/potassium intake

History of $\mathrm{HDP}$ and $\mathrm{Na} / \mathrm{K}$ intake

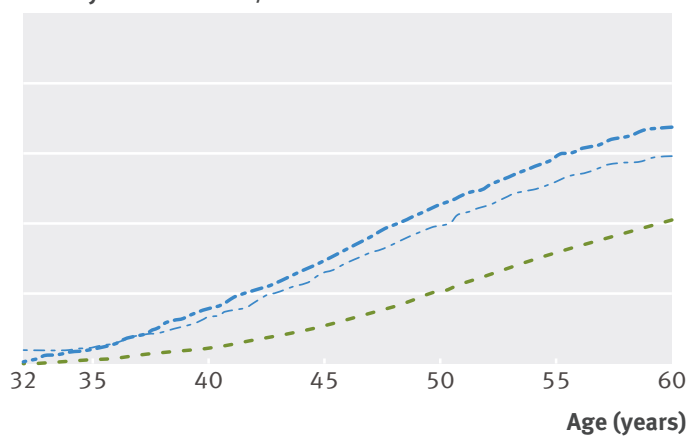

Fig 1 | Cumulative incidence of chronic hypertension in parous women by lifestyle risk factors and history of hypertensive disorders of pregnancy (HDP). For body mass index (BMI), the comparison is between women with low normal weight (18.5-22.4) and women with obesity class I (30.0-34.9). For Dietary Approaches to Stop Hypertension (DASH) diet and physical activity, the comparison is first versus fourth quarter, and for sodium/ potassium, the comparison is fourth versus first quarter. Survival data shown here are prepared for regression

\begin{tabular}{|c|c|c|c|c|c|c|c|c|c|}
\hline & \multirow{2}{*}{$\begin{array}{l}\text { Events/ } \\
\text { person } \\
\text { years }\end{array}$} & \multicolumn{5}{|c|}{ BMI category*: hazard ratio $(95 \% \mathrm{Cl})$} & \multicolumn{3}{|l|}{$P$ value } \\
\hline & & $18.5-22.4$ & $22.5-24.9$ & $25.0-29.9$ & $30.0-34.9$ & $\geq 35.0$ & Trendt & $\begin{array}{l}\text { Additive } \\
\text { interaction‡ }\end{array}$ & $\begin{array}{l}\text { Multiplicative } \\
\text { interaction }\end{array}$ \\
\hline \multicolumn{10}{|c|}{ Age $32-39$ years } \\
\hline No HDP & $571 / 88542$ & 1.00 (reference) & $1.92(1.45$ to 2.54$)$ & $4.31(3.33$ to 5.58$)$ & $6.67(4.94$ to 9.01$)$ & $10.32(7.33$ to 14.52$)$ & $<0.001$ & \multirow{2}{*}{$<0.001$} & \multirow[t]{2}{*}{0.71} \\
\hline History of HDP & $270 / 11401$ & 1.00 (reference)§ & $2.13(1.27$ to 3.58$)$ & $3.54(2.20$ to 5.68$)$ & $5.92(3.59$ to 9.76$)$ & $8.66(5.15$ to 14.56$)$ & $<0.001$ & & \\
\hline \multicolumn{10}{|c|}{ Age $40-49$ years } \\
\hline No HDP & $5695 / 329956$ & 1.00 (reference) & $1.52(1.38$ to 1.67$)$ & $2.69(2.47$ to 2.93$)$ & $4.78(4.34$ to 5.26$)$ & $6.92(6.20$ to 7.72$)$ & $<0.001$ & \multirow{2}{*}{$<0.001$} & \multirow[t]{2}{*}{$<0.001$} \\
\hline History of HDP & $1336 / 32406$ & 1.00 (reference)§ & $1.47(1.17$ to 1.86$)$ & 2.44 (1.99 to 3.00$)$ & $3.54(2.86$ to 4.40$)$ & $4.53(3.62$ to 5.66$)$ & $<0.001$ & & \\
\hline \multicolumn{10}{|c|}{ Age $50-59$ years } \\
\hline No HDP & $5343 / 202605$ & 1.00 (reference) & $1.38(1.25$ to 1.51$)$ & $2.26(2.07$ to 2.47$)$ & $3.35(3.03$ to 3.70$)$ & $5.03(4.48$ to 5.65$)$ & $<0.001$ & 0.009 & 0.44 \\
\hline History of HDP & $700 / 14624$ & 1.00 (reference)§ & 1.59 (1.16 to 2.18$)$ & 2.10 (1.57 to 2.79$)$ & 3.28 (2.43 to 4.42$)$ & 4.61 (3.36 to 6.31$)$ & $<0.001$ & & \\
\hline \multicolumn{10}{|c|}{$\begin{array}{l}\text { BMI=body mass index; HDP=hypertensive disorders of pregnancy. } \\
\text { Models include adjustment for age, race/ethnicity (white, Latina, African-American, Asian, or other), parity (1,2, or } \geq 3 \text { births), Dietary Approaches to Stop Hypertension diet (quarters), physical } \\
\text { activity (quarters), BMI at age } 18 \text { years, smoking (non-smoker, current smoker, or former smoker), alcohol intake (none, } 1-15 \mathrm{~g} / \text { day, }>15 \mathrm{~g} / \text { day), non-steroidal anti-inflammatory drug use (none, } \\
\text { past, current), history of gestational diabetes mellitus (yes/no), menopausal status (premenopausal, postmenopausal, unsure), parental history of chronic hypertension (yes/no), and interaction } \\
\text { terms between HDP and BMI categories. } \\
\text { *Underweight women (BMK } 18.5 \text { ) excluded as additive interaction analyses require category with lowest combined risk to be reference group. } \\
\text { tContinuous BMI included in models instead of categorical BMI. } \\
\text { fGlobal P for relative excess risk due to interaction (RERI) between HDP and BMI. Specific additive interaction statistics are given in supplementary table C. } \\
\text { §Same model as for “No HDP" except that women with previous HDP and BMI } 18.5-22.4 \text { constitute reference group. Focus of main interaction analysis is on additive rate scale. This type of } \\
\text { interaction is tested within RERI framework by using "No HDP" model and does not correspond to comparing hazard ratios presented here by HDP history. }\end{array}$} \\
\hline
\end{tabular}
analyses, which are divided into three separate Cox proportional hazards models by age: 32-39, 40-49, and 50-59 years

Table 2 | Association between body mass index and chronic hypertension in parous women within categories of history of hypertensive disorders of pregnancy presented as multivariable adjusted hazard ratios by age 


\begin{tabular}{|c|c|c|c|c|c|c|c|c|}
\hline \multirow[b]{3}{*}{ Physical activity } & \multirow{3}{*}{$\begin{array}{l}\text { Events/ } \\
\text { person } \\
\text { years }\end{array}$} & \multirow{2}{*}{\multicolumn{4}{|c|}{ Quarters*: hazard ratio $(95 \% \mathrm{Cl})$}} & \multicolumn{3}{|l|}{ P value } \\
\hline & & & & & & \multirow[t]{2}{*}{ Trendt } & \multirow[t]{2}{*}{$\begin{array}{l}\text { Additive } \\
\text { interaction }\end{array}$} & \multirow[t]{2}{*}{$\begin{array}{l}\text { Multiplicative } \\
\text { interaction }\end{array}$} \\
\hline & & Fourth (high) & Third & Second & First & & & \\
\hline \multicolumn{9}{|l|}{ Age $32-39$ years: } \\
\hline No HDP & $572 / 90887$ & 1.00 (reference) & 1.16 (0.91 to 1.49$)$ & 1.12 (0.87 to 1.43$)$ & 1.10 (0.86 to 1.42$)$ & 0.26 & \multirow[t]{2}{*}{0.14} & \multirow[t]{2}{*}{0.28} \\
\hline Previous HDP & $272 / 11549$ & 1.00 (reference)§ & 1.43 (1.00 to 2.02$)$ & 1.03 (0.71 to 1.48$)$ & $0.92(0.63$ to 1.34$)$ & 0.35 & & \\
\hline \multicolumn{9}{|l|}{ Age $40-49$ years: } \\
\hline No HDP & $5716 / 334976$ & 1.00 (reference) & $1.07(0.98$ to 1.16$)$ & $1.05(0.97$ to 1.13$)$ & $1.10(1.01$ to 1.19$)$ & 0.004 & \multirow[t]{2}{*}{0.67} & \multirow{2}{*}{0.72} \\
\hline Previous HDP & $1343 / 32646$ & 1.00 (reference)§ & $1.12(0.95$ to 1.32$)$ & 1.01 (0.85 to 1.19$)$ & $1.06(0.90$ to 1.24$)$ & 0.55 & & \\
\hline \multicolumn{9}{|l|}{ Age $50-59$ years: } \\
\hline No HDP & $5366 / 205207$ & 1.00 (reference) & 0.95 (0.87 to 1.02$)$ & 1.00 (0.93 to 1.09$)$ & $0.99(0.91$ to 1.07$)$ & 0.59 & \multirow[t]{2}{*}{0.50} & \multirow[t]{2}{*}{0.47} \\
\hline Previous HDP & $702 / 14723$ & 1.00 (reference)§ & $1.05(0.84$ to 1.31$)$ & $0.99(0.79$ to 1.24$)$ & $1.13(0.91$ to 1.41$)$ & 0.12 & & \\
\hline DASH diet score & & Fourth (high) & Third & Second & First & & & \\
\hline \multicolumn{9}{|l|}{ Age $32-39$ years: } \\
\hline No HDP & $572 / 90887$ & 1.00 (reference) & 1.27 (0.96 to 1.69$)$ & $1.37(1.03$ to 1.82$)$ & $1.50(1.15$ to 1.97$)$ & 0.007 & \multirow[t]{2}{*}{0.48} & \multirow[t]{2}{*}{0.31} \\
\hline Previous HDP & $272 / 11549$ & 1.00 (reference)§ & $1.13(0.77$ to 1.66$)$ & $0.89(0.59$ to 1.34$)$ & $1.15(0.79$ to 1.68$)$ & 0.26 & & \\
\hline \multicolumn{9}{|l|}{ Age $40-49$ years: } \\
\hline No HDP & $5716 / 334976$ & 1.00 (reference) & 1.15 (1.06 to 1.25$)$ & 1.18 (1.08 to 1.28$)$ & 1.31 (1.21 to 1.42$)$ & $<0.001$ & \multirow[t]{2}{*}{0.04} & \multirow[t]{2}{*}{0.04} \\
\hline Previous HDP & $1343 / 32646$ & 1.00 (reference)§ & $1.25(1.06$ to 1.48$)$ & $1.02(0.85$ to 1.21$)$ & $1.21(1.03$ to 1.43$)$ & 0.08 & & \\
\hline \multicolumn{9}{|l|}{ Age $50-59$ years: } \\
\hline No HDP & $5366 / 205207$ & 1.00 (reference) & 1.19 (1.10 to 1.29$)$ & $1.26(1.16$ to 1.36$)$ & $1.28(1.18$ to 1.40$)$ & $<0.001$ & \multirow[t]{2}{*}{0.41} & \multirow[t]{2}{*}{0.46} \\
\hline Previous HDP & $702 / 14723$ & 1.00 (reference)§ & $1.02(0.82$ to 1.27$)$ & $1.17(0.94$ to 1.45$)$ & $1.29(1.03$ to 1.60$)$ & 0.01 & & \\
\hline \multicolumn{2}{|c|}{ Sodium/potassium intake } & First (low) & Second & Third & \multicolumn{2}{|l|}{ Fourth } & & \\
\hline \multicolumn{9}{|c|}{ Age $32-39$ years: } \\
\hline No HDP & $572 / 90887$ & 1.00 (reference) & $1.07(0.82$ to 1.40$)$ & 0.98 (0.75 to 1.27$)$ & 1.07 (0.83 to 1.38$)$ & 0.65 & 0.88 & 0.87 \\
\hline Previous HDP & $272 / 11549$ & 1.00 (reference)§ & $1.14(0.76$ to 1.71$)$ & $1.16(0.79$ to 1.69$)$ & $1.11(0.76$ to 1.62$)$ & 0.68 & & \\
\hline Age $40-49$ years: & & & & & & & & \\
\hline No HDP & $5716 / 334976$ & 1.00 (reference) & 1.04 (0.96 to 1.13) & $1.10(1.02$ to 1.19$)$ & 1.09 (1.00 to 1.18$)$ & 0.03 & 0.84 & 0.58 \\
\hline Previous HDP & $1343 / 32646$ & 1.00 (reference)§ & 1.01 (0.85 to 1.19) & 0.98 (0.84 to 1.15$)$ & $1.00(0.85$ to 1.17$)$ & 0.72 & & \\
\hline Age $50-59$ years: & & & & & & & & \\
\hline No HDP & $5366 / 205207$ & 1.00 (reference) & $1.07(0.99$ to 1.15$)$ & $1.14(1.05$ to 1.23$)$ & $1.11(1.02$ to 1.20$)$ & 0.006 & 0.88 & 0.88 \\
\hline Previous HDP & $702 / 14723$ & 1.00 (reference)§ & $1.03(0.82$ to 1.28$)$ & $1.08(0.87$ to 1.33$)$ & $1.14(0.92$ to 1.42$)$ & 0.11 & & \\
\hline $\begin{array}{l}\text { DASH=Dietary Appro } \\
\text { Models generally inc } \\
22.5-24.9,25-29.9 \\
>15 \mathrm{~g} / \text { day), non-ste } \\
\text { history of chronic hy } \\
\text { for its definition. Ins } \\
{ }^{*} \text { Descending physic } \\
+ \text { tLifestyle factor incl } \\
\text { ‡Global P for relative } \\
\text { §Same model as for } \\
\text { scale. This type of in }\end{array}$ & $\begin{array}{l}\text { S to Stop Hypertensic } \\
\text { adjustment for age, } \\
4.9, \geq 35 \text { ), physical a } \\
\text { nti-inflammatory dru } \\
\text { nsion (yes/no), and i } \\
\text { fuarters of whole gra } \\
\text { vity and DASH diet s } \\
\text { in model as continuo } \\
\text { sS risk due to interac } \\
\text { IDP" except that won } \\
\text { ion is tested within R }\end{array}$ & $\begin{array}{l}\text { on; HDP=hypertensive } \\
\text { ethnicity (white, Latina, } \\
\text { activity (quarters), bod } \\
\text { ug use (none, past, curr } \\
\text { interaction terms betwe } \\
\text { ains and saturated fat } \\
\text { score but ascending sod } \\
\text { ous variable (sodium/p } \\
\text { ction (RERI) between H } \\
\text { men with previous HDP } \\
\text { RERI framework by usin }\end{array}$ & $\begin{array}{l}\text { disorders of pregnancy. } \\
\text { African-American, Asian, } \\
\text { mass index at age } 18 \text { ye } \\
\text { ent), history of gestationa } \\
\text { en HDP and lifestyle facto } \\
\text { ere used to adjust for diet } \\
\text { ium/potassium intake. } \\
\text { tassium intake and physi }\end{array}$ & $\begin{array}{l}\text { or other), parity }(1,2 \text {, or } \geq \\
\text { ars, smoking (non-smoker } \\
\text { I diabetes mellitus (yes } / n \\
\text { or quarters. DASH diet is n } \\
\text { tary habits. } \\
\text { ical activity as metabolic }\end{array}$ & $\begin{array}{l}3 \text { pregnancies), DASH di } \\
\text { current smoker, or forme } \\
\text { ), menopausal status (pr } \\
\text { tincluded in models of } \\
\text { quivalents are log transfo } \\
\text { eraction statistics are giv }\end{array}$ & $\begin{array}{l}\text { t (quarters) } \\
\text { r smoker), } \\
\text { emenopaus } \\
\text { odium/potc } \\
\text { rmed). }\end{array}$ & $\begin{array}{l}\text { body mass index } \\
\text { lcohol intake (no } \\
\text { al, postmenopaus } \\
\text { ssium intake as s }\end{array}$ & $\begin{array}{l}(<18,18-22.4, \\
\text { e, } 1-15 \mathrm{~g} / \text { day, } \\
\text { l, unsure), parental } \\
\text { dium intake is usec } \\
\text { s is on additive rate }\end{array}$ \\
\hline
\end{tabular}

the additive scale, which is relevant in the context of understanding the potential to prevent chronic hypertension. In contrast, we found evidence of a negative multiplicative interaction between previous HDP and body mass index among women aged 40-49 years, indicating that the hazard ratio for chronic hypertension in women with previous HDP was smaller than expected with higher body mass index compared with women without HDP. These analyses of multiplicative interaction are informative regarding to what extent the hazard ratio estimates differ between women with and without HDP, but less relevant as basis for mechanistic inference. ${ }^{28}$ We found no clear evidence of effect modification (interaction) by physical activity, DASH diet, or sodium/potassium intake on either the additive or multiplicative scale (table 3). The exception is that in women aged 40-49 years, some evidence existed of interactions between adherence to DASH diet and history of HDP. In supplementary tables $\mathrm{C}$ and $\mathrm{D}$, we show additional interaction statistics (RERI, attributable proportion, and synergy index) for each joint exposure category. For example, the proportion of risk of chronic hypertension attributable to the additive interaction between HDP and body mass index (attributable proportion) ranged from $16 \%$ to $51 \%$ across age and body mass index categories.
Figure 2 shows estimates for the relative excess risk of chronic hypertension due to HDP history and body mass index (synthesized from models in table 2 and supplementary table $\mathrm{C}$ ). In each panel of figure 2, the white bar corresponds to the reference group of women with low normal body mass index and no history of HDP (hazard ratio=1). The combined white and light blue bars in each panel indicate the hazard ratio for women with low normal body mass index but with a history of HDP. The medium blue bar indicates the relative excess risk due to body mass index above low normal for women without HDP history. Finally, the dark blue bars correspond to the RERI, which is consistently positive across the three panels. These dark blue bars indicate the relative excess risk of chronic hypertension associated with higher rather than low normal body mass index that is particular to women with a history of HDP.

We also did several sensitivity analyses: adjustment for parents' education during the participant's childhood, use of oral contraceptives (in women aged 32 to 49 years), or hormone replacement therapy (in women aged 50 to 59 years) did not materially alter the findings (data not shown). In addition, the results remained very similar when we restricted the analysis to person time of women with no history of gestational diabetes mellitus, and the 
Relative excess risk due to interaction (RERI) of BMI and HDP Relative excess risk due to BMI

$\square$ Relative excess risk due to HDP

$\square$ Reference risk (BMI 18.5-22.4 and no history of HDP) RERIs are shown with $95 \%$ confidence intervals
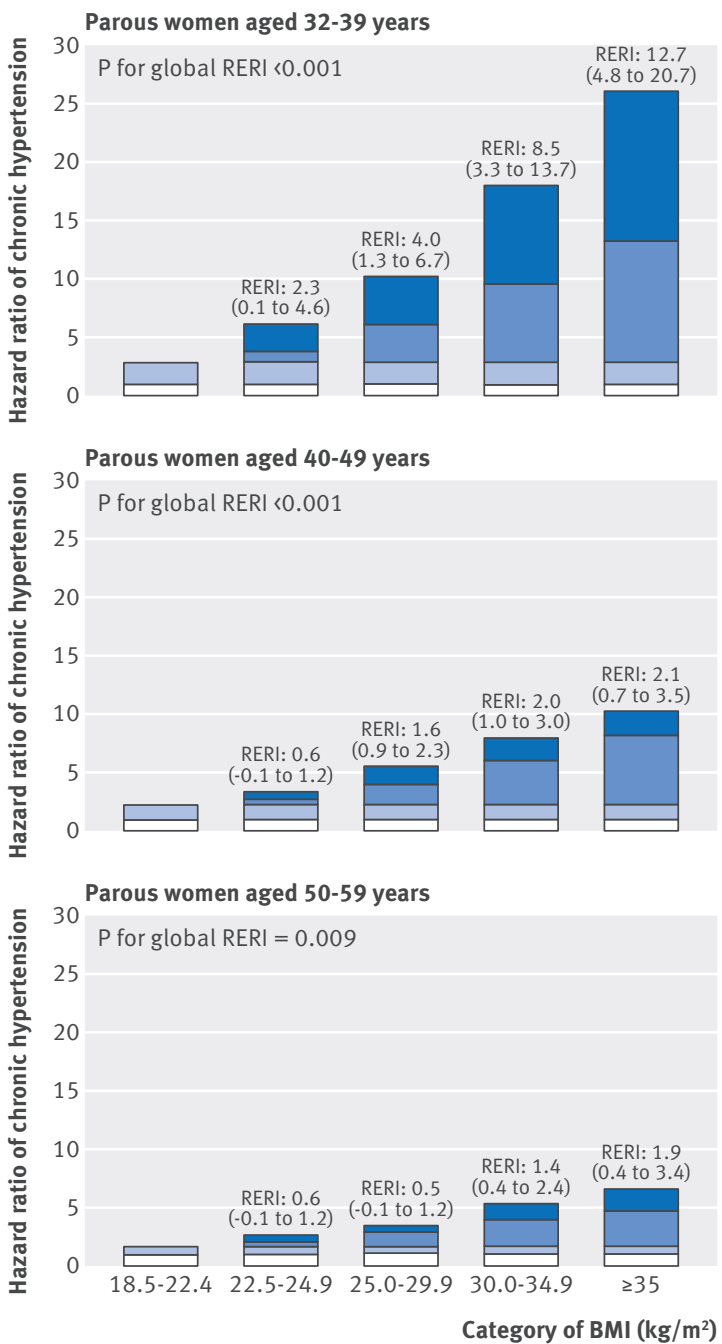

Fig 2 | Additive interaction of body mass index (BMI) and history of hypertensive disorders of pregnancy (HDP) on risk of chronic hypertension in women by age and $\mathrm{BMI}$ presented as hazard ratios partitioned into relative excess risks due to BMI, HDP, and their interaction (RERI). For each category of BMI, relative excess risk due to each risk factor (BMI or HDP) and their additive interaction (RERI) are shown; the latter is supported if RERI >0. For example, in women with $B M I \geq 35.0, R E R I$ is calculated as: $\mathrm{RERI}_{\mathrm{BMI} 235.0}=\mathrm{HR}_{\mathrm{BMI} 235.0, \mathrm{HDP}}-\mathrm{HR}_{\mathrm{BMI} 18.5 \text { to 22.4, } \mathrm{HDP}}-\mathrm{HR}_{\mathrm{BMI} 235.0 \text {, }}$ No HDP +1 . All hazard ratios are adjusted for age, race/ ethnicity, parity, history of gestational diabetes mellitus, diet, physical activity, non-steroidal anti-inflammatory drug use, menopausal status, alcohol, smoking, and parental history of chronic hypertension

additive interaction between HDP history and body mass index also persisted in analyses with body mass index as a continuous variable (data not shown).

\section{Discussion}

In this study, overweight and obesity were associated with increased risk of chronic hypertension in women with and without a history of hypertensive pregnancy. Furthermore, a higher than normal weight also seemed to be a (positive and additive) effect modifier on the association between HDP and chronic hypertension. In other words, women with both overweight/obesity and history of HDP had a higher than expected risk of chronic hypertension, given the risks observed when these risk factors were considered separately. Hypertensive pregnancy may be an early warning sign of an adverse cardiometabolic composition, which temporarily manifests under the metabolic stress of pregnancy. ${ }^{30}$ Our findings suggest that this adverse cardiometabolic phenotype, revealed by a history of HDP, may synergize with overweight and obesity in the years after pregnancy to further raise the risk of chronic hypertension later in life. A healthy weight thus seems to be of additional importance in women with a history of HDP. Consequently, interventions focused on weight optimization could potentially reduce the risk of chronic hypertension to a greater extent in this group than among other parous women.

We found no support for effect modification by physical activity, DASH diet, or sodium/potassium intake on the association between previous HDP and the development of chronic hypertension. Given the inconsistent RERI pattern observed across quarters of DASH diet adherence in women aged 40-49 years (supplementary table D), we interpret the low $\mathrm{P}$ value for global RERI in this age group to be a chance finding. In the absence of effect modification, it is best to assume that current recommendations to prevent chronic hypertension through diet and exercise apply to women with previous HDP as they do to women without a history of HDP. Furthermore, even though physical activity in itself might not decrease the risk of chronic hypertension in all women, it is still a logical target behavior to reduce weight in all preventive interventions focusing on chronic hypertension. The somewhat inconsistent results of diet and physical activity with risk of chronic hypertension may also result from low statistical power to detect modest effect sizes when stratified by age and HDP history. In addition, the sodium/potassium intake calculated from the diets reported by the participants is high compared with the recommended sodium/potassium intake for a low salt diet. ${ }^{18}$ As a result, we did not have the data to investigate the association between a very low salt diet and risk of chronic hypertension.

\section{Strengths and weaknesses of study}

To our knowledge, this is the first analysis to comprehensively investigate lifestyle in the progression from HDP to chronic hypertension over decades of follow-up. The large sample size, available data on several confounders, and the ability to update lifestyle and disease information over follow-up are key strengths. The primary weakness of the study is the reliance on nurse participants' self report of HDP exposure. Although the self reported diagnosis of chronic hypertension has been shown to be highly accurate in the Nurses' Health Studies, ${ }^{26} 31$ 
we have less information about the validity of self reported pre-eclampsia and gestational hypertension. However, in primary care practice, a woman's self report of pregnancy complications is typically the only information that a clinician has about a woman's pregnancy history; in this sense, HDP ascertainment in this study mimics the clinical situation. The study population consists largely of white nurses, potentially limiting generalizability, and additional studies in more diverse populations are needed to further confirm our results. Another potential limitation is that not all in the original cohort provided detailed reproductive history, which included our HDP exposure, and that any participant had to be alive in 2009 to do so. However, as all cohort participants were, or would have been, still in their middle age at that time point, survivor bias is unlikely to explain the results.

\section{Comparison with other studies and implications of findings}

Obesity has long been viewed as a major risk factor for hypertension in younger middle aged women. ${ }^{32}$ Our findings are consistent with literature showing that women with a history of HDP are at a higher risk of developing chronic hypertension and that higher body mass index may be a mediator of chronic hypertension in women with a history of HDP. ${ }^{33} 34$ However, we are not aware of any other study that includes formal interaction analyses between HDP and post-pregnancy body mass index for the risk of chronic hypertension. Our analyses suggest potential synergy between HDP history and overweight/obesity in the development of chronic hypertension. If certain assumptions hold (for example, a risk factor never being preventive or "positive risk monotonicity"), interaction on the additive scale might support the presence of mechanistic interaction and potential synergy in a sufficient cause framework. ${ }^{35} 36$ Although the synergy between HDP history and obesity is merely suggestive and based on observational data, previous studies offer some biological underpinning for this finding. For example, insulin resistance, leptin dysregulation, and sympathetic hyperactivity are features shared by HDP and obesity. ${ }^{37} 38$ Dysfunction in the interplay of these factors is also involved in the development of chronic hypertension in people with obesity. ${ }^{39}$ In the reproductive context, obesity and supra-normal weight gain are also associated with increased risk of complications both in a current pregnancy and in future pregnancies. ${ }^{40-42}$ Furthermore, women with HDP tend to gain more weight in the decades after childbirth, ${ }^{43}$ which supports the need for effective post-pregnancy interventions in these women. Although maintaining normal weight, adherence to a DASH-type diet, lower sodium intake, and adequate levels of physical activity are generally recommended for women to decrease their cardiovascular risk, this study is, to our knowledge, the first to specifically confirm that these recommendations are also suitable for middle aged women with previous HDP.
Our observations suggest that overweight and obesity are especially detrimental to women with previous HDP and also provide evidence for targeted clinical screening and interventions in these women. However, women with a history of HDP might be more insulin resistant, ${ }^{44}$ which, in concert with potentially altered energy homeostasis, might impede sustained, long term, weight loss. ${ }^{45}$ Thus, whereas women with overweight and a history of HDP have a higher than expected risk of chronic hypertension, they might also be less responsive to clinical weight loss interventions. This underlines the importance of testing specific interventions in clinical trials before implementing them more broadly. Here we provide important rationale and data for the development of such studies. In focus groups, women with a history of pre-eclampsia and gestational diabetes have expressed interest in lifestyle interventions that include the whole family unit. $^{4647}$ As HDP and gestational diabetes are also associated with poor cardiometabolic profiles in the offspring, ${ }^{48} 49$ a healthy maternal weight might reduce the risk of cardiometabolic disease in two generations. Family based interventions are of additional interest in this context, as they have shown promising results for reducing overweight and obesity in offspring. ${ }^{50}$ Interestingly, in a study that specifically targeted the parents of obese 2-5 year old children, the intervention was associated with improved weight change in the offspring and parental weight loss. ${ }^{51}$ Lifestyle interventions following pregnancy complications, therefore, might be most effective if they also include primordial cardiovascular disease prevention in the offspring.

\section{Conclusions}

This is the first study to comprehensively assess the relative importance of lifestyle factors in the progression to chronic hypertension in women with a history of HDP compared with parous women without such a history. A history of HDP is associated with a higher risk of chronic hypertension, and our data suggest that overweight or obesity might be especially detrimental to affected women. In contrast, we found no evidence that physical activity or dietary quality differ in their importance in preventing chronic hypertension by HDP history. Therefore, to reduce cardiometabolic risk in women with a history of HDP, our results suggest that effective clinical interventions that facilitate a healthy weight and lifestyle post-pregnancy are needed. In the meantime, clinicians should especially help women with a history of HDP or gestational diabetes mellitus to attain, and maintain, a healthy weight after pregnancy. Each woman's own reproductive plans should guide whether the main motivation of such efforts is to prepare for a healthy future pregnancy or to lower the risk of future cardiometabolic disease.

Contributors: ST, JWRE, and PWF acquired funding for the study. ST, JWRE, JJS, LJT, EBR, and PWF designed the study. ST did the statistical analyses. ST and JWRE drafted the first version of the manuscript. ST, JWRE, JJS, LJT, EBR, and PWF provided critical input on the manuscript and approved the final version for publication. ST and JWRE are the guarantors. 
Funding: ST is supported by an international postdoctoral grant from the Swedish Research Council. Additional project funding was granted by Bundy Academy, Lund, Sweden; Folksam Research Foundation, Sweden; the Swedish Heart and Lung Association; Anna Lisa and Sven Erik Lundgren's Foundation, Sweden; Hulda and E Conrad Mossfelt's Foundation, Sweden. The Nurses' Health Study II cohort is supported by an infrastructure grant (UM1 CA176726). The study funders did not have any role in the study design; in the collection, analysis, and interpretation of data; in the writing of the report; or in the decision to submit the article for publication. JJS is supported by a grant from the National Institutes of Health (NHLBI T32 HL 098048). All investigators are independent from funders.

Competing interests: All authors have completed the ICMJE uniform disclosure form at www.icmje.org/coi disclosure.pdf and declare: no support from any organization for the submitted work; no financial relationships with any organizations that might have an interest in the submitted work in the previous three years; no other relationships or activities that could appear to have influenced the submitted work.

Ethical approval: The study was approved by the Institutional Review Board at Brigham and Women's Hospital. Completion of the self administered questionnaire was considered to imply informed consent.

Data sharing: No additional data available.

Transparency declaration: ST and JWRE affirm that this manuscript is an honest, accurate, and transparent account of the study being reported; that no important aspects of the study have been omitted; and that any discrepancies from the study as planned (and, if relevant, registered) have been explained.

This is an Open Access article distributed under the terms of the Creative Commons Attribution IGO License (https://creativecommons. org/licenses/by-nc/3.0/igo/), which permits use, distribution, and reproduction for non-commercial purposes in any medium, provided the original work is properly cited.

1 Lim SS, Vos T, Flaxman AD. A comparative risk assessment of burden of disease and injury attributable to 67 risk factors and risk factor clusters in 21 regions, 1990-2010: a systematic analysis for the Global Burden of Disease Study 2010. Lancet 2012;380:2224-60. doi:10.1016/S0140-6736(12)61766-8

2 Mosca L, Benjamin EJ, Berra K. American Heart Association. Effectiveness-based guidelines for the prevention of cardiovascular disease in women-2011 update: a guideline from the American Heart Association. J Am Coll Cardiol 2011;57:1404-23. doi:10.1016/j.jacc.2011.02.005

3 Samuels-Kalow ME, Funai EF, Buhimschi C. Prepregnancy body mass index, hypertensive disorders of pregnancy, and long-term maternal mortality. Am J Obstet Gynecol 2007;197:490.e1-6. doi:10.1016/ j.ajog.2007.04.043

4 Wikström A-K, Haglund B, Olovsson M, Lindeberg SN. The risk of maternal ischaemic heart disease after gestational hypertensive disease. BJOG 2005;112:1486-91. doi:10.1111/ j.1471-0528.2005.00733.x

5 Heida KY, Franx A, van Rijn BB. Earlier Age of Onset of Chronic Hypertension and Type 2 Diabetes Mellitus After a Hypertensive Disorder of Pregnancy or Gestational Diabetes Mellitus. Hypertension 2015;66:1116-22

6 Männistö T, Mendola P, Vääräsmäki M. Elevated blood pressure in pregnancy and subsequent chronic disease risk. Circulation 2013;127:681-90. doi:10.1161/CIRCULATIONAHA.112.128751

Rich-Edwards JW, Fraser A, Lawlor DA, Catov JM. Pregnancy characteristics and women's future cardiovascular health: an underused opportunity to improve women's health? Epidemiol Rev 2014:36:57-70. doi:10.1093/epirev/mxt006

8 Piepoli MF, Hoes AW, Agewall S, Authors/Task Force Members. 2016 European Guidelines on cardiovascular disease prevention in clinical practice: The Sixth Joint Task Force of the European Society of Cardiology and Other Societies on Cardiovascular Disease Prevention in Clinical Practice (constituted by representatives of 10 societies and by invited experts)Developed with the special contribution of the European Association for Cardiovascular Prevention \& Rehabilitation (EACPR). Eur Heart J 2016;37:2315-81. doi:10.1093/eurheartj/ ehw106

9 American College of Obstetricians and GynecologistsTask Force on Hypertension in Pregnancy. Hypertension in pregnancy. Report of the American College of Obstetricians and Gynecologists' Task Force on Hypertension in Pregnancy. Obstet Gynecol 2013;122:1122-31.

10 Fraser A, Nelson SM, Macdonald-Wallis C. Associations of pregnancy complications with calculated cardiovascular disease risk and cardiovascular risk factors in middle age: the Avon Longitudinal Study of Parents and Children. Circulation 2012;125:1367-80. doi:10.1161/CIRCULATIONAHA.111.044784
11 Spaan J, Peeters L, Spaanderman M, Brown M. Cardiovascular risk management after a hypertensive disorder of pregnancy. Hypertension 2012;60:1368-73. doi:10.1161/ HYPERTENSIONAHA.112.198812

12 Seely EW, Tsigas E, Rich-Edwards JW. Preeclampsia and future cardiovascular disease in women: How good are the data and how can we manage our patients? Semin Perinatol 2015;39:276-83. doi:10.1053/j.semperi.2015.05.006

13 Landsberg L, Aronne LJ, Beilin LI. Obesity-related hypertension: pathogenesis, cardiovascular risk, and treatment-a position paper of the The Obesity Society and The American Society of Hypertension. Obesity (Silver Spring) 2013;21:8-24. doi:10.1002/oby.20181

14 Cornelissen VA, Fagard RH, Coeckelberghs E, Vanhees L. Impact of resistance training on blood pressure and other cardiovascular risk factors: a meta-analysis of randomized, controlled trials. Hypertension 2011;58:950-8. doi:10.1161/ HYPERTENSIONAHA.111.177071

15 Carnethon MR, Evans NS, Church TS. Joint associations of physical activity and aerobic fitness on the development of incident hypertension: coronary artery risk development in young adults. Hypertension 2010;56:49-55. doi:10.1161/ HYPERTENSIONAHA.109.147603

16 Sacks FM, Svetkey LP, Vollmer WM. DASH-Sodium Collaborative Research Group. Effects on blood pressure of reduced dietary sodium and the Dietary Approaches to Stop Hypertension (DASH) diet. N Engl I Med 2001:344:3-10. doi:10.1056/NEIM200101043440101

17 Moore TJ, Conlin PR, Ard J, Svetkey LP. DASH (Dietary Approaches to Stop Hypertension) diet is effective treatment for stage 1 isolated systolic hypertension. Hypertension 2001;38:155-8. doi:10.1161/01.HYP.38.2.155

18 Adrogué HJ, Madias NE. Sodium and potassium in the pathogenesis of hypertension. N Engl J Med 2007;356:1966-78. doi:10.1056/ NEJMra064486

19 Stuart JJ, Bairey Merz CN, Berga SL. Maternal recall of hypertensive disorders in pregnancy: a systematic review. J Womens Health (Larchmt)2013;22:37-47. doi:10.1089/jwh.2012.3740

20 Rimm EB, Stampfer MJ, Colditz GA, Chute CG, Litin LB, Willett WC Validity of self-reported waist and hip circumferences in men and women. Epidemiology 1990;1:466-73. doi:10.1097/00001648 199011000-00009

21 Troy LM, Hunter DJ, Manson JE, Colditz GA, Stampfer MJ, Willett WC. The validity of recalled weight among younger women. Int J Obes Relat Metab Disord 1995;19:570-2.

22 World Health Organization. Obesity: preventing and managing the global epidemic: report of a WHO consultation.WHO, 2000

23 Wolf AM, Hunter DJ, Colditz GA. Reproducibility and validity of a self-administered physical activity questionnaire. Int J Epidemiol 1994:23:991-9. doi:10.1093/ije/23.5.991

24 Tobias DK, Hu FB, Chavarro J, Rosner B, Mozaffarian D, Zhang C. Healthful dietary patterns and type 2 diabetes mellitus risk among women with a history of gestational diabetes mellitus. Arch Intern Med 2012;172:1566-72. doi:10.1001/archinternmed.2012.3747

25 Freedman LS, Commins JM, Moler JE. Pooled results from 5 validation studies of dietary self-report instruments using recovery biomarkers for potassium and sodium intake. Am J Epidemiol 2015;181:473-87. doi:10.1093/aje/kwu325

26 Forman JP, Curhan GC, Taylor EN. Plasma 25-hydroxyvitamin D levels and risk of incident hypertension among young women. Hypertension 2008;52:828-32. doi:10.1161/HYPERTENSIONAHA.108.117630

27 Li R, Chambless L. Test for additive interaction in proportional hazards models. Ann Epidemiol 2007;17:227-36. doi:10.1016/ j.annepidem.2006.10.009

$28 \mathrm{Knol}$ MJ, Vander Weele TJ. Recommendations for presenting analyses of effect modification and interaction. Int J Epidemiol 2012;41: 514-20. doi:10.1093/ije/dyr218

29 Knol MJ, Vander Weele TJ, Groenwold RHH, Klungel OH, Rovers MM Grobbee DE. Estimating measures of interaction on an additive scale for preventive exposures. Eur I Epidemiol 2011:26:433-8. doi:10.1007/s10654-011-9554-9

30 Sattar N, Greer IA. Pregnancy complications and maternal cardiovascular risk: opportunities for intervention and screening? BMJ 2002-325:157-60 doi:10.1136/bmj.325.7356.157

31 Colditz GA, Martin P, Stampfer MJ. Validation of questionnaire information on risk factors and disease outcomes in a prospective cohort study of women. Am I Epidemiol 1986:123:894-900. doi:10.1093/oxfordjournals.aje.a114319

32 Garrison RJ, Kannel WB, Stokes I 3rd, Castelli WP. Incidence and precursors of hypertension in young adults: the Framingham Offspring Study. Prev Med 1987;16:235-51. doi:10.1016/0091 7435(87)90087-9

33 Bellamy L, Casas J-P, Hingorani AD, Williams DJ. Pre-eclampsia and risk of cardiovascular disease and cancer in later life: systematic review and meta-analysis. BMJ 2007;335:974. doi:10.1136/ bmj.39335.385301.BE

34 Magnussen EB, Vatten LI Smith GD, Romundstad PR. Hypertensive disorders in pregnancy and subsequently measured cardiovascular 
risk factors. Obstet Gynecol 2009;114:961-70. doi:10.1097/ AOG.0b013e3181bbodfc

35 VanderWeele TJ. Sufficient cause interactions and statistical interactions. Epidemiology 2009;20:6-13. doi:10.1097/ EDE.0b013e31818f69e7

36 VanderWeele TJ. Causal interactions in the proportional hazards model. Epidemiology 2011;22:713-7. doi:10.1097/ EDE.0b013e31821db503

37 Kaaja RJ, Pöyhönen-Alho MK. Insulin resistance and sympathetic overactivity in women. J Hypertens 2006;24:131-41. doi:10.1097/01.hjh.0000194121.19851.e5

38 Feldstein C, Julius S. The complex interaction between overweight, hypertension, and sympathetic overactivity. I Am Soc Hypertens 2009;3:353-65. doi:10.1016/j.jash.2009.10.001

39 Hall JE, da Silva AA, do Carmo JM. Obesity-induced hypertension: role of sympathetic nervous system, leptin, and melanocortins. J Biol Chem 2010;285:17271-6. doi:10.1074/jbc.R110.113175

40 Cnattingius S, Bergström R, Lipworth L, Kramer MS. Prepregnancy weight and the risk of adverse pregnancy outcomes. N Engl J Med 1998:338:147-52. doi:10.1056/NEIM199801153380302

41 Villamor E, Cnattingius S. Interpregnancy weight change and risk of adverse pregnancy outcomes: a population-based study. Lancet 2006:368:1164-70 doi:10.1016/S0140-6736(06)69473-7

42 Thorsdottir I, Torfadottir JE, Birgisdottir BE, Geirsson RT. Weight gain in women of normal weight before pregnancy: complications in pregnancy or delivery and birth outcome. Obstet Gynecol 2002;99:799-806

43 Callaway LK, McIntyre HD, O'Callaghan M, Williams GM, Najman JM, Lawlor DA. The association of hypertensive disorders of pregnancy with weight gain over the subsequent 21 years: findings from a prospective cohort study. Am J Epidemiol 2007;166:421-8. doi:10.1093/aje/kwm099

44 Girouard J, Giguère Y, Moutquin J-M, Forest JC. Previous hypertensive disease of pregnancy is associated with alterations of markers of insulin resistance. Hypertension 2007;49:1056-62. doi:10.1161/ HYPERTENSIONAHA.107.087528

45 Morton GJ, Meek TH, Schwartz MW. Neurobiology of food intake in health and disease. Nat Rev Neurosci 2014;15:367-78. doi:10.1038/nrn3745

46 Skurnik G, Roche AT, Stuart IJ. Improving the postpartum care of women with a recent history of preeclampsia: a focus group study. Hypertens Pregnancy 2016;35:371-81. doi:10.3109/ 10641955.2016.1154967

47 Nicklas JM, Zera CA, Seely EW, Abdul-Rahim ZS, Rudloff ND, Levkoff SE. Identifying postpartum intervention approaches to prevent type 2 diabetes in women with a history of gestational diabetes. BMC Pregnancy Childbirth 2011:11:23. doi:10.1186/1471-239311-23

48 Fraser A, Nelson SM, Macdonald-Wallis C, Sattar N, Lawlor DA Hypertensive disorders of pregnancy and cardiometabolic health in adolescent offspring. Hypertension 2013;62:614-20. doi:10.1161/ HYPERTENSIONAHA.113.01513

49 Boney CM, Verma A, Tucker R, Vohr BR. Metabolic syndrome in childhood: association with birth weight, maternal obesity, and gestational diabetes mellitus. Pediatrics 2005;115:e290-6. doi:10.1542/peds.2004-1808

50 West F, Sanders MR, Cleghorn GJ, Davies PS. Randomised clinical trial of a family-based lifestyle intervention for childhood obesity involving parents as the exclusive agents of change. Behav Res Ther 2010;48:1170-9. doi:10.1016/j.brat.2010.08.008

51 Quattrin T, Roemmich JN, Paluch R, Yu J, Epstein LH, Ecker MA. Treatment outcomes of overweight children and parents in the medical home. Pediatrics 2014;134:290-7. doi:10.1542/ peds.2013-4084

Supplementary material: Supplementary tables A-D 